J. Amer. Soc. Hort. Sci. 118(2):263-268. 1993.

\title{
Chilling of Endodormant Peach Propagules: IV. Terminal Shoot Growth of Cuttings, Including Gibberellic Acid Treatments
}

\author{
James W. Frisby ${ }^{1}$ and Schuyler D. Seeley ${ }^{2}$ \\ Plants, Soils, and Biometeorology Department, Utah State University, Logan, UT 84322-4820
}

\begin{abstract}
Additional index words. Prunus persica, temperature responses, forcing, chilling requirement, dormancy
Abstract. Cuttings from peach (Prunus persica (L.) Batch cv. Johnson Elberta) trees were subjected to five chilling durations (20 to 76 days) at seven temperatures ( 0 to 14C) and five concentrations of gibberellic acid [GA, (0.0 to 1 mM)]. There was a significant increase in terminal shoot length with longer chilling treatments. Cuttings treated at 2 to SC had the longest shoots, and shoot length decreased, in order, following treatment at 10,0 , and $14 \mathrm{C}$. Treatment with the highest concentration of GA, resulted in the longest terminal shoots. Interactions between $\mathbf{G A}_{3}$ and chilling durations indicated that either higher concentrations of GA, or longer chilling treatments increased terminal shoot growth. Thus, endogenous promoters, like GA, are evidently produced or released during chilling. Sensitivity to GA, was also important. Chemical name used: Gibberellic acid (GA3).
\end{abstract}

Endodormancy release is usually measured by an arbitrary percentage of budbreak in a specified amount of time. Shoot growth may also be used as an indicator of dormancy completion, even though some believe that a bud is either dormant (not growing perceptibly) or nondormant, despite the speed of subsequent shoot growth (Berrie, 1984). Such a definition does not account for delayed foliation of peach trees that have not receive adequate chilling (Chandler et al., 1937), nor does it account for the bellshaped, rest-intensity curve reported by Hatch and Walker (1969).

GA appears to be one of the important controls of endodormancy release and is considered to be antagonistic to dormancy. Levels of GA in peach seeds and buds increase with chilling treatments, but not at nonchilling temperatures (Gianfagna and Rachmiel, 1986; Mathur et al., 1971; Seeley, 1976). Gibberellic acid concentrations have been used to determine dormancy intensity of vegetative buds on cuttings (Couvillon and Hendershott, 1974; Hatch and Walker, 1969). Interactions between abscisic acid (ABA) and GA have also been investigated in seeds (Bulard, 1985; Mehanna et al., 1985).

This study was designed to test the effect of chilling duration, temperature, and exogenously applied GA, on terminal shoot growth of endodormant peach cuttings. Data were subsequently used to compare the chilling responses of cuttings with those of seeds and seedlings (Frisby and Seeley, 1993c).

\section{Materials and Methods}

Terminal shoots (200 to $250 \mathrm{~mm}$ long), with both flower and leaf buds, were collected from mature 'Johnson Elberta' peach trees growing at the Utah State Univ. Experiment Station, Kaysville, in early Fall 1987 (7 Oct.). According to the Utah Chill Unit Model (Richardson et al., 1974), no chill units had been accumulated at this time (J. LaMar Anderson, personal communication).

Remaining leaves were removed by hand, and the cuttings were soaked for one hour in a N-trichloromethylthio-4-cyclohexene-

Received for publication 4 Feb. 1992. Accepted for publication 1 Sept. 1992. This report is based, in part, on research conducted and supported as part of SAES Western Regional Research Project W-130. Utah Agr. Expt. Sta. J. Paper no. 4268. The use of trade names does not imply endorsement of the products used nor criticism of similar ones not mentioned. The cost of publishing this paper was defrayed in part by the payment of page charges. Under postal regulations, this paper therefore must be hereby marked advertisement solely to indicate this fact. 'Graduate Research Assistant.

${ }^{2}$ Professor. 1,2-dicarboximide (Captan) suspension [0.3\% a.i. (w/v)]. The cuttings were divided into groups (62 cuttings each) and placed in plastic bags (3.8 liter capacity) that contained vermiculite (1 liter) moistened with captan suspension [0.3\% a.i. (w/v), $250 \mathrm{ml}]$. Bags were sealed and placed in cardboard boxes to exclude light.

Treatments were arranged in factorial treatment combinations of eight temperatures ( 0 to $18 \mathrm{C}$ ), five durations (20 to 76 days), and five GA concentrations ( 0 to $1.0 \mathrm{~mm}$ ) in a completely randomized design followed by repeated measures during forcing time (6 to 20 days).

Three boxes were randomly assigned to each temperature treatment $(0,2,4,6,8,10,14$, and 18C). Boxes were placed in temperature controlled chambers described by Frisby and Seeley (1993a). Bags in the 0C chamber were wrapped with aluminum foil because the chamber was too small for cardboard boxes.

Chilling treatment durations ranged from 20 to 76 days at 14day intervals. At each duration, the bags were opened and 10 cuttings were removed from each box (30 from each temperature). The cuttings were rinsed in tap water. Cuttings for each temperature were divided into groups of six and bound and submerged (apical end down, covering up to $160 \mathrm{~mm}$ ) for $1 \mathrm{~h}$ in GA, [Eastman Organic Chemical, Rochester, N.Y. (concentration assumed 100\% for calculation purposes)] solutions $(0.0,0.03,0.1,0.3$, and 1.0 $\mathrm{mm}$ ) in glass containers. Fresh GA, solutions were prepared for each chilling duration.

Cutting bases were cut off $(10 \mathrm{~mm})$ under tap water, and cuttings were placed individually in test tubes $(15 \times 80 \mathrm{~mm})$ containing deionized water. Test tubes were randomly placed in styrofoam holders in a greenhouse ( 37 to $38 \mathrm{~cm} *$ per test tube). Greenhouse conditions were as described by Frisby and Seeley (1993b). Test tubes were filled to overflowing with deionized water every 2 to 3 days. Measurements of terminal shoot growth (bud scales to the longest leaf tip) were taken $6,8,13,15$, and 20 days after forcing.

A factorial univariate repeated measures analysis of variance (ANOVA) was used to analyze the data (Littell, 1989). Trend analysis was calculated for the main effects and important significant interactions.

\section{Results and Discussion}

The 18C treatment promoted very little growth, and many of the cuttings died. Some of the cuttings were visibly infected with 

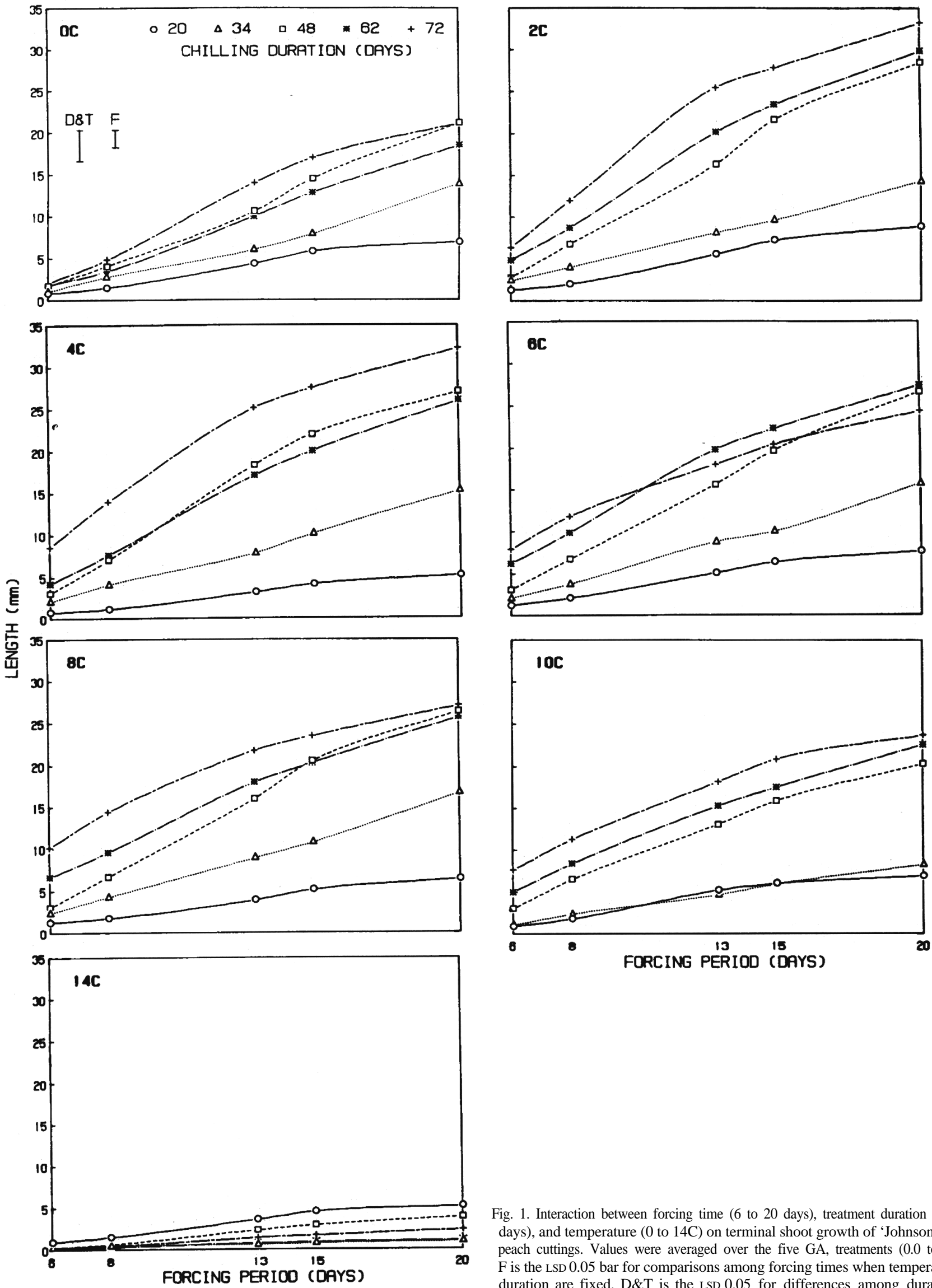

Fig. 1. Interaction between forcing time (6 to 20 days), treatment duration (20 to 76 days), and temperature (0 to 14C) on terminal shoot growth of 'Johnson Elberta' peach cuttings. Values were averaged over the five GA, treatments ( 0.0 to $1 \mathrm{~mm})$. $\mathrm{F}$ is the LSD 0.05 bar for comparisons among forcing times when temperature and duration are fixed. D\&T is the LSD 0.05 for differences among duration and temperature conditions when forcing times are fixed. Trend analysis is provided in Table 1. 

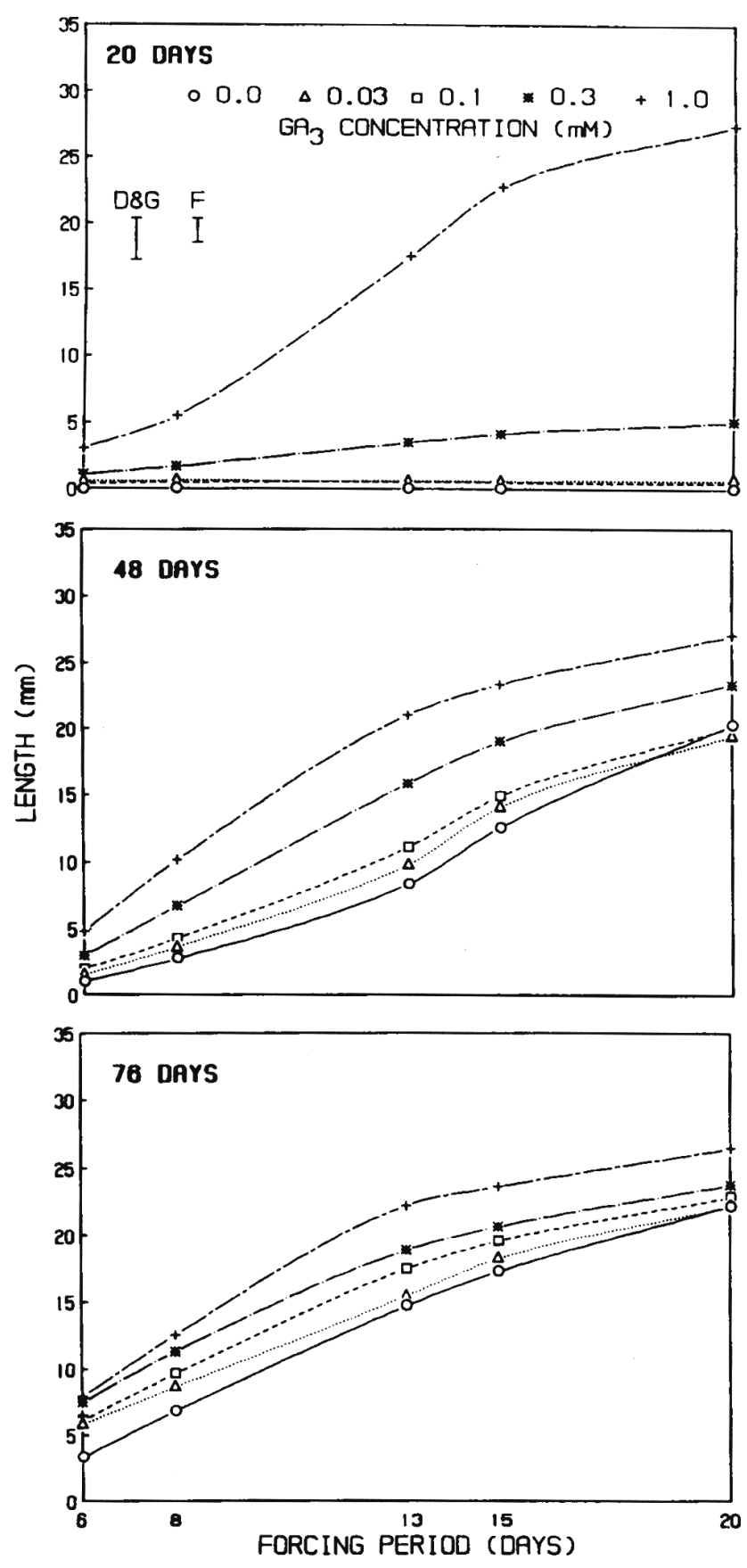

fungi. The lack of growth at this temperature could have been due to the temperature treatment or to the fungal contamination. Because of these problems, the $18 \mathrm{C}$ treatment was not used in the ANOVA. The 18C treatment was not expected to promote growth.

Other problem data points were treated as follows: if the cutting died after forcing, then terminal shoot growth was assumed to be zero; if the terminal bud was damaged before forcing, then the average of the other replications for that treatment was used; if the terminal shoot or cutting died after growth began, then the length of the shoot before death was used for subsequent forcing measurements. An appropriate decrease of the degrees of freedom was used to adjust for missing data (Table 1).

Due to the many temperature treatments, all replications for each temperature were treated in one temperature controlled chamber simultaneously. We understand that this underestimated
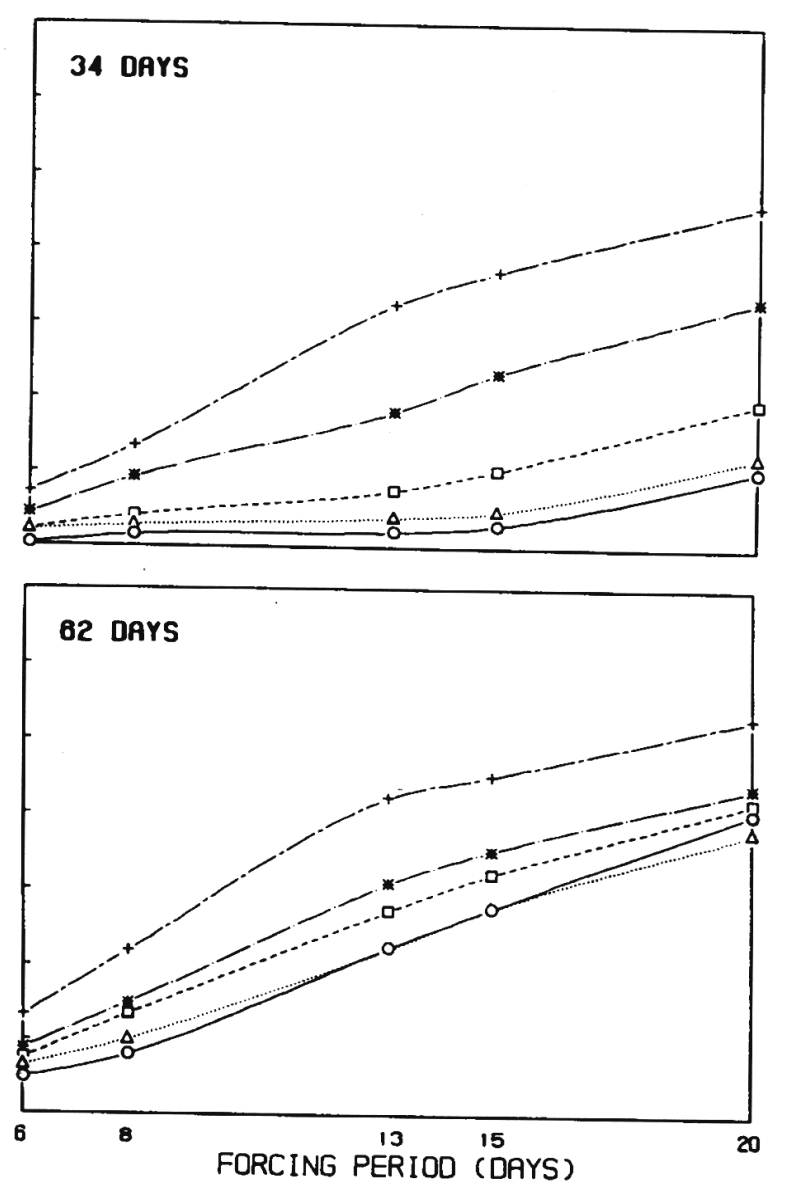

Fig. 2. Interaction between forcing time (6 to 20 days), treatment duration (20 to 76 days), and $\mathrm{GA}_{3}$ concentration ( 0.0 to $\left.1.0 \mathrm{~mm}\right)$ on terminal shoot growth of 'Johnson Elberta' peach cuttings. Values were averaged over the seven treatment temperatures ( 0 to $14 \mathrm{C}) . \mathrm{F}$ is the LSD 0.05 bar for comparisons among forcing times when GA, concentration and duration are fixed. D\&G is the LSD 0.05 bar for differences among duration and GA, concentration combinations when forcing times are fixed. Trend analysis is provided in Table 1.

the error terms for the true variability of the systems. Yet, probability values were so low that the results were clearly significant (Table 1). Also, because cuttings from each duration came out of chilling at different times, the results may be confounded with greenhouse conditions. Four sets of temperature data were gathered during the experiment (unshielded chart recorders). There was not a significant growing degree hour (GDH) difference between these sets of temperature data [GDH calculated by the method of Richardson et al., 1975 (data not presented)].

All main effects and the two-way interactions of the main-plot were significant (Table 1). The three-way interaction between treatment duration, temperature, and the GA, concentration was not significant. All the two-way interactions and the three-way interactions with forcing time were significant. Only the significant three-way interactions are presented. 

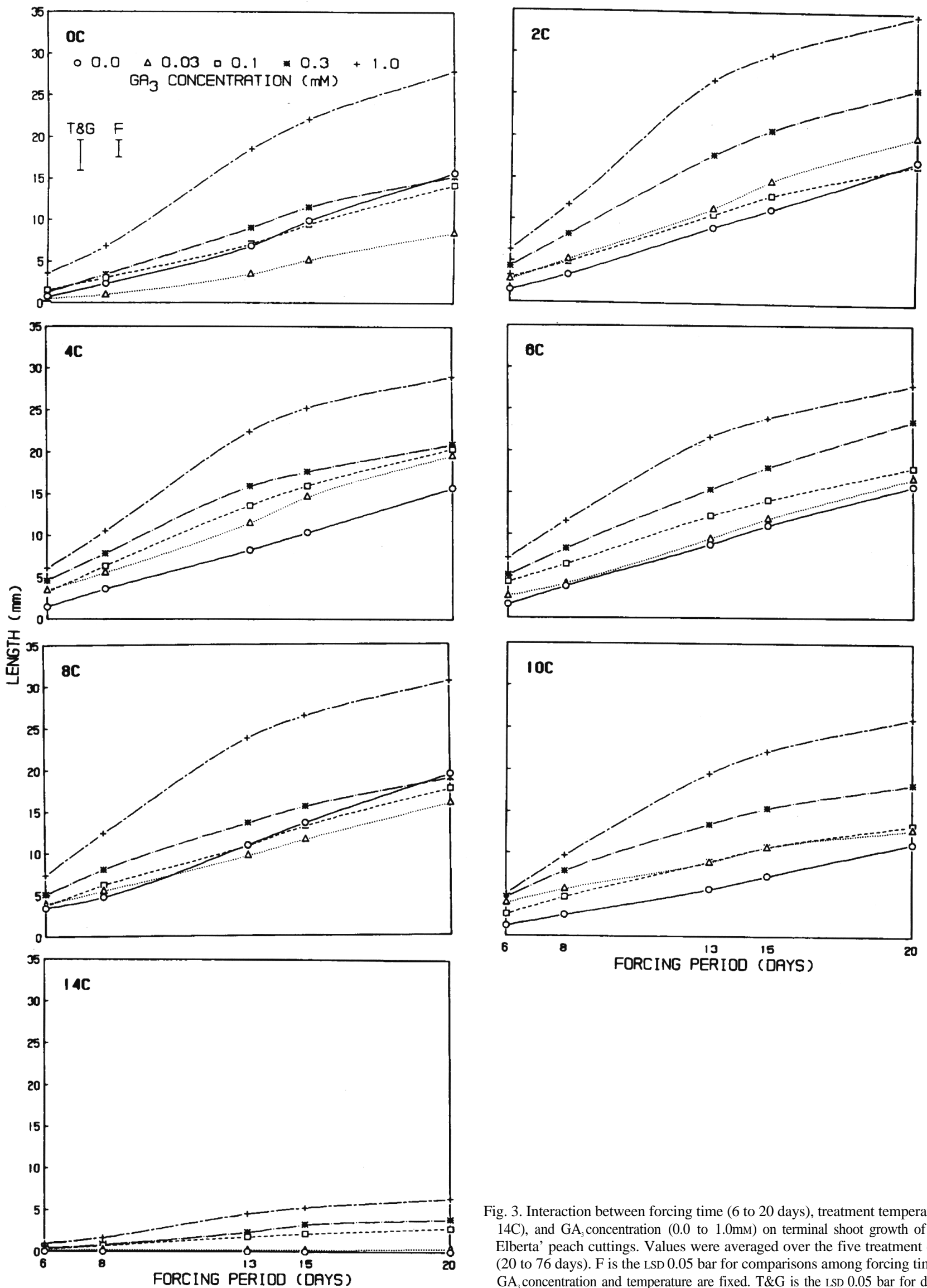

Fig. 3. Interaction between forcing time ( 6 to 20 days), treatment temperature ( 0 to $14 \mathrm{C}$ ), and $\mathrm{GA}_{3}$ concentration ( 0.0 to $\left.1.0 \mathrm{~mm}\right)$ on terminal shoot growth of 'Johnson Elberta' peach cuttings. Values were averaged over the five treatment durations (20 to 76 days). $F$ is the LSD 0.05 bar for comparisons among forcing times when $\mathrm{GA}_{3}$ concentration and temperature are fixed. T\&G is the LSD 0.05 bar for differences among temperature and GA, concentration combinations when forcing times are fixed. Trend analysis is provided in Table 1. 
Table 1. Univariate repeated measures ANOVA for terminal shoot growth (in millimeters) of 'Johnson Elberta' peach cuttings in response to factorial treatment combinations of chilling durations $(20,34,48,62$, and 76 days), temperatures $(0,2,4,6,8,10$, and 14C), and GA, treatments $(0.0,0.03,0.1,0.03$, and $1.0 \mathrm{mM})$ in a completely randomized design followed by repeated measures during forcing time $(6,8,13,15$, and 20 days). Linear and polynomial trend analysis is provided for main effects and important interactions.

\begin{tabular}{|c|c|c|c|}
\hline Source of variation & $\mathrm{df}$ & Adjusted $\mathrm{df}^{\mathrm{z}}$ & MS \\
\hline Duration (D) & 4 & 4 & \\
\hline Linear $\left(_{1}\right)$ & & 1 & $90823.7^{* * *}$ \\
\hline Quadratic $\left({ }_{q}\right)$ & & 1 & $1449.2^{* *}$ \\
\hline Cubic & & 1 & $220.8^{\mathrm{NS}}$ \\
\hline Quartic & & 1 & $3511.1^{* * *}$ \\
\hline Temperature $(\mathrm{T})$ & 6 & 6 & \\
\hline Linear & & 1 & $27041.7^{* * *}$ \\
\hline Quadratic & & 1 & $45793.1^{* * *}$ \\
\hline Cubic & & 1 & $44.3^{\mathrm{Ns}}$ \\
\hline Residual & & 3 & $1171.41^{* * *}$ \\
\hline $\mathrm{GA}_{3}(\mathrm{G})$ & 4 & 4 & \\
\hline Linear & & 1 & $62874.0^{* * *}$ \\
\hline Quadratic & & 1 & $1199.7^{*}$ \\
\hline Cubic & & 1 & $26.7^{\mathrm{NS}}$ \\
\hline Quartic & & 1 & $9.0^{\mathrm{NS}}$ \\
\hline $\mathrm{D} \times \mathrm{T}$ & 24 & 24 & \\
\hline $\mathrm{D}_{1} \times \mathrm{T}_{1}$ & & 1 & $6528.2^{* * *}$ \\
\hline $\mathrm{D}_{1} \times \mathrm{T}_{\mathrm{q}}$ & & 1 & $16342.6^{* * *}$ \\
\hline $\mathrm{D}_{\mathrm{q}} \times \mathrm{T}_{1}^{\mathrm{q}}$ & & 1 & $414.5^{\mathrm{NS}}$ \\
\hline $\mathrm{D}_{\mathrm{q}}^{\mathrm{q}} \times \mathrm{T}_{\mathrm{q}}$ & & 1 & $644.7^{\mathrm{NS}}$ \\
\hline Residual & & 20 & $258.0^{\mathrm{NS}}$ \\
\hline $\mathrm{D} \times \mathrm{G}$ & 16 & 16 & \\
\hline $\mathrm{D}_{1} \times \mathrm{G}_{1}$ & & 1 & $9381.0^{* * *}$ \\
\hline $\mathrm{D}_{1} \times \mathrm{G}_{\mathrm{q}}$ & & 1 & $253.1^{\mathrm{NS}}$ \\
\hline $\mathrm{D}_{\mathrm{q}} \times \mathrm{G}_{1}^{\mathrm{q}}$ & & 1 & $424.1^{\mathrm{NS}}$ \\
\hline $\mathrm{D}_{\mathrm{q}}^{\mathrm{q}} \times \mathrm{G}_{\mathrm{q}}$ & & 1 & $721.5^{\mathrm{NS}}$ \\
\hline Residual & & 12 & $123.4^{\mathrm{NS}}$ \\
\hline $\mathrm{T} \times \mathrm{G}$ & 24 & 24 & \\
\hline $\mathrm{T}_{1} \times \mathrm{G}_{1}$ & & 1 & $2808.5^{* * *}$ \\
\hline $\mathrm{T}_{1} \times \mathrm{G}_{\mathrm{q}}$ & & 1 & $22.2^{\mathrm{NS}}$ \\
\hline $\mathrm{T}_{\mathrm{q}} \times \mathrm{G}_{1}^{\mathrm{q}}$ & & 1 & $1051.0^{*}$ \\
\hline $\mathrm{T}_{q}^{\mathrm{q}} \times \mathrm{G}_{\mathrm{q}}$ & & 1 & $150.4^{\mathrm{NS}}$ \\
\hline Residual & & 20 & $262.4^{\mathrm{NS}}$ \\
\hline $\mathrm{D} \times \mathrm{T} \times \mathrm{G}$ & 96 & 96 & $187.2^{\mathrm{NS}}$ \\
\hline Error (a) & 875 & 870 & 200.1 \\
\hline Forcing time $(\mathrm{F})$ & 4 & 4 & \\
\hline Linear & & 1 & $138849.5^{* * *}$ \\
\hline Quadratic & & 1 & $1394.0^{* * *}$ \\
\hline Cubic & & 1 & $74.4^{*}$ \\
\hline Quartic & & 1 & $0.0^{\mathrm{NS}}$ \\
\hline Error (b) & 20 & 20 & 13.9 \\
\hline $\mathrm{D} \times \mathrm{F}$ & 16 & 16 & $1248.3^{* * *}$ \\
\hline $\mathrm{T} \times \mathrm{F}$ & 24 & 24 & $788.3^{* * *}$ \\
\hline$G \times F$ & 16 & 16 & $749.6^{* * *}$ \\
\hline $\mathrm{D} \times \mathrm{T} \times \mathrm{F}$ & 96 & 96 & \\
\hline $\mathrm{D}_{1} \times \mathrm{T}_{1} \times \mathrm{F}_{1}$ & & 1 & $2331.5^{* * *}$ \\
\hline $\mathrm{D}_{1} \times \mathrm{T}_{1} \times \mathrm{F}_{\mathrm{q}}$ & & 1 & $152.3^{* *}$ \\
\hline $\mathrm{D}_{1} \times \mathrm{T}_{\mathrm{q}} \times \mathrm{F}_{1}^{\mathrm{q}}$ & & 1 & $763.3^{* * *}$ \\
\hline $\mathrm{D}_{1} \times \mathrm{T}_{\mathrm{q}}^{\mathrm{q}} \times \mathrm{F}_{\mathrm{q}}$ & & 1 & $74.7^{*}$ \\
\hline $\mathrm{D}_{\mathrm{q}} \times \mathrm{T}_{1}^{4} \times \mathrm{F}_{1}^{4}$ & & 1 & $286.2^{* * *}$ \\
\hline $\mathrm{D}_{\mathrm{q}} \times \mathrm{T}_{1} \times \mathrm{F}_{\mathrm{q}}$ & & 1 & $57.8^{\mathrm{NS}}$ \\
\hline $\mathrm{D}_{\mathrm{q}}^{\mathrm{q}} \times \mathrm{T}_{\mathrm{q}} \times \mathrm{F}_{1}$ & & 1 & $1192.9^{* * *}$ \\
\hline $\mathrm{D}_{\mathrm{q}} \times \mathrm{T}_{\mathrm{q}}^{\mathrm{q}} \times \mathrm{F}_{\mathrm{q}}$ & & 1 & $33.1^{\mathrm{NS}}$ \\
\hline Residual & & 88 & $21.0^{*}$ \\
\hline $\mathrm{D} \times \mathrm{G} \times \mathrm{F}$ & 64 & 64 & \\
\hline
\end{tabular}




\begin{tabular}{|c|c|c|c|}
\hline Source of variation & df & Adjusted $\mathrm{df}^{2}$ & MS \\
\hline $\mathrm{D}_{1} \times \mathrm{G}_{1} \times \mathrm{F}_{1}$ & & 1 & $7434.1^{* * *}$ \\
\hline$D_{1} \times G_{1} \times F_{9}$ & & 1 & $10.1^{\mathrm{NS}}$ \\
\hline $\mathrm{D}_{1} \times \mathrm{G}_{\mathrm{q}} \times \mathrm{F}_{1}$ & & 1 & $11.0^{\mathrm{NS}}$ \\
\hline $\mathrm{D}_{1} \times \mathrm{G}_{\mathrm{q}}^{\mathrm{q}} \times \mathrm{F}_{\mathrm{q}}$ & & 1 & $19.7^{\mathrm{NS}}$ \\
\hline$D_{q} \times G_{1}^{4} \times F_{1}^{q}$ & & 1 & $1173.1^{* * *}$ \\
\hline $\mathrm{D}_{\mathrm{q}}^{\mathrm{q}} \times \mathrm{G}_{1} \times \mathrm{F}_{1}$ & & 1 & $125.5^{* *}$ \\
\hline $\mathrm{D}_{\mathrm{q}}^{\mathrm{q}} \times \mathrm{G}_{\mathrm{q}} \times \mathrm{F}_{1}$ & & 1 & $437.8^{* * *}$ \\
\hline $\mathrm{D}_{\mathrm{q}}^{\mathrm{q}} \times \mathrm{G}_{\mathrm{q}}^{\mathrm{q}} \times \mathrm{F}_{\mathrm{q}}$ & & 1 & $45.8^{\mathrm{NS}}$ \\
\hline Residual & & 56 & $19.4^{\mathrm{NS}}$ \\
\hline $\mathrm{T} \times \mathrm{G} \times \mathrm{F}$ & 96 & 96 & \\
\hline $\mathrm{T}_{1} \times \mathrm{G}_{1} \times \mathrm{F}_{1}$ & & 1 & $409.4^{* * *}$ \\
\hline $\mathrm{T}_{1} \times \mathrm{G}_{1} \times \mathrm{F}_{\mathrm{q}}$ & & 1 & $144.4^{* *}$ \\
\hline $\mathrm{T}_{1} \times \mathrm{G}_{\mathrm{q}} \times \mathrm{F}_{1}$ & & . 1 & $42.2^{\mathrm{NS}}$ \\
\hline $\mathrm{T}_{1} \times \mathrm{G}_{\mathrm{q}}^{\mathrm{q}} \times \mathrm{F}_{\mathrm{q}}$ & & 1 & $8.3^{\mathrm{NS}}$ \\
\hline $\mathrm{T}_{\mathrm{q}} \times \mathrm{G}_{1}^{4} \times \mathrm{F}_{1}^{4}$ & & 1 & $4.6^{\mathrm{NS}}$ \\
\hline $\mathrm{T}_{\mathrm{q}}^{\mathrm{q}} \times \mathrm{G}_{1} \times \mathrm{F}_{\mathrm{q}}$ & & 1 & $71.1^{*}$ \\
\hline $\mathrm{T}_{\mathrm{q}}^{\mathrm{q}} \times \mathrm{G}_{\mathrm{q}}^{1} \times \mathrm{F}_{1}^{\mathrm{q}}$ & & 1 & $11.4^{\mathrm{NS}}$ \\
\hline $\mathrm{T}_{\mathrm{q}}^{\mathrm{q}} \times \mathrm{G}_{\mathrm{q}}^{\mathrm{q}} \times \mathrm{F}_{\mathrm{q}}$ & & 1 & $0.8^{\mathrm{NS}}$ \\
\hline Residual & & 88 & $22.8^{* *}$ \\
\hline $\mathrm{D} \times \mathrm{T} \times \mathrm{G} \times \mathrm{F}$ & 384 & 384 & $13.8^{\mathrm{NS}}$ \\
\hline Error (c) & 3480 & 3450 & 15.7 \\
\hline Total & 5249 & & \\
\hline
\end{tabular}

The interaction between treatment duration, temperature, and forcing time on shoot growth indicated better growth with longer treatments at chilling temperatures [0 to $10 \mathrm{C}$ (Fig. 1.)]. Shoot growth was the best after chilling at 2 or $4 \mathrm{C}$ for 76 days. Shoot growth after treatment at $14 \mathrm{C}$, not considered a chilling temperature, was low and did not improve after longer treatments. The largest change in growth over forcing time occurred between 34 and 48 days of chilling. Chilling treatments longer than 48 days induced better shoot growth after less forcing time.

The chilling requirement of 'Elberta' peach flower buds is reported to be 37 days at $6 \mathrm{C}$ [880 chill units (Richardson et al., 1974)]. Our data suggests that terminal vegetative buds respond to a wider range of chilling temperatures (0 to 10C). A chilling requirement of 37 days appears to be a minimum rather than a maximum requirement for vegetative growth (Frisby and Seeley, 1993c).

The interaction between treatment duration, GA, concentration, and forcing time indicated that the highest GA, concentration (1.0 $\mathrm{mM}$ ) promoted the best growth (Fig. 2). Shoot growth after treatment with $1.0 \mathrm{~mm} \mathrm{GA}$, did not improve with longer chilling treatments. At the lower concentrations ( 0.0 to $0.3 \mathrm{~mm}$ ), shoot growth improved with longer chilling treatments. In fact, shoot growth of cuttings treated with $1.0 \mathrm{~mm} \mathrm{GA}$, was only slightly better than that of the controls ( 0 mm GA,) chilled for 76 days. This result gives strong evidence for endogenous production or release of growth promoters during chilling. These results agree with data for apple seed reported by Bulard (1985).

However, the interaction between treatment temperature, GA, concentration, and the forcing time indicated that some chilling is needed before the cuttings responded to GA, (Fig. 3). Cuttings treated at $14 \mathrm{C}$ did not respond to the GA, treatments, which suggests that sensitivity to GA, was important. Treatment for only 20 days at 0 to $10 \mathrm{C}$ overcame this sensitivity-related problem (Figs. 2 and Fig. 3).

\section{Literature Cited}

Berrie, A.M.M. 1984. Germination and dormancy, p. 440-468. In: M.B. Wilkins (ed.). Advanced plant physiology. Pitman Publishing, Marshfield, Mass.

Bulard, C. 1985. Intervention by gibberellin and cytokinin in the release of apple embryos from dormancy: A reappraisal. New Phytol. 101:241-249.

Couvillon, G.A. and C.H. Hendershott. 1974. A characterization of the "After-rest" period of flower buds of two peach cultivars of different chilling requirements. J. Amer. Soc. Hort. Sci. 99:23-26.

Chandler, W.H., M.H. Kimball, G.L. Philp, W.P. Tufts, and G.P. Weldon. 1937. Chilling requirements for opening of buds on deciduous orchard trees and some other plants in California. Univ. of California, Berkeley, Bul. 611.

Frisby, J.W. and SD. Seeley. 1993a. Chilling of endodormant peach propagules: I. Seed germination and emergence. J. Amer. Soc. Hort. Sci. 118:248-252.

Frisby, J.W. and S.D. Seeley. 1993b. Chilling of endodormant peach propagules: III. Budbreak and subsequent growth of physiologically dwarfed to near normal seedlings. J. Amer. Soc. Hort. Sci. 118:258-262.

Frisby, J.W. and S.D. Seeley. 1993c. Chilling of endodormant peach propagules: V. Comparisons between seeds, seedlings, and cuttings. J. Amer. Soc. Hort. Sci. 118:269-273

Gianfagna, T.J. and S. Rachmiel. 1986. Changes in gibberellin-like substances of peach during stratification. Physiol. Plant. 66:154-158.

Hatch, A.H. and D.R. Walker. 1969. Rest intensity of dormant peach and apricot leaf buds as influenced by temperature, cold hardiness and respiration. J. Amer. Soc. Hort. Sci. 94:304-307.

Mathur, D.D., G.A. Couvillon, H.M. Vines, and C.H. Hendershott. 1971. Stratification effects on endogenous gibberellic acid (GA) in peach seeds. HortScience 6:538-539.

Littell, R.C. 1989. Statistical analysis of experiments with repeated measurements. HortScience 24:37-40.

Mehanna, H.T., G.C. Martin, and C. Nishijima. 1985. Effects of temperature, chemical treatments and endogenous hormone content on peach seed germination and subsequent seedling growth. Scientia Hort. 27:63-73

Richardson, E.A., S.D. Seeley, and D.R. Walker. 1974. A model for estimating the completion of rest for 'Redhaven' and 'Elberta' peach trees. HortScience 9:331332.

Richardson, E.A., S.D. Seeley, D.R. Walker, J.L Anderson, and G.L. Ashcroft. 1975. Pheno-climatography of spring peach bud development. HortScience 10:236-237.

Seeley, E.J. 1976. Application of instrumental gibberellic acid analysis techniques: With special reference to gibberellic acids in after-ripening peach seeds and developing flower buds. PhD Diss., Utah State Univ., Logan. 